\section{\$1. Microstructural Control for Improving Properties of V-4Cr-4Ti Alloys}

Muroga, T., Nagasaka, T.,

Zheng, P.F. (Grad. Univ. Advanced Studies), Chen, J.M. (SWIP)

Vanadium alloy is well known as a promising candidate low activation structural material for nuclear fusion reactors. Based on long-standing studies, V-4Cr-4Ti was selected as the leading candidate. Relative to near term candidate of Reduced Activation Feritic/Martensitic Steel (RAFM), the operation temperature of vanadium alloys will be higher by $100-150 \mathrm{~K}$ enabling higher thermal efficiency as the power generation plant. Among the major reasons for limiting upper temperature limit for the use of vanadium alloys is thermal creep deformation. Recent studies showed appropriate thermal and mechanical treatments can suppress the thermal creep deformation of $\mathrm{V}-4 \mathrm{Cr}-4 \mathrm{Ti}$ especially in high applied stress regimes.

From the microstructural viewpoints, the thermal and mechanical treatments induce formation or dissolution of Ti-rich precipitates and introduction of dislocations. The role of these imperfections in the deformation process is the key to improvement of the properties. This paper reviews precipitate evolution in various thermal and mechanical treatments and its impact on mechanical properties for $\mathrm{V}-4 \mathrm{Cr}-4 \mathrm{Ti}$ alloys.

The manufacturing of $\mathrm{V}-4 \mathrm{Cr}-4 \mathrm{Ti}$ alloy (NIFSHEAT-2) products in the Japanese program proceeded with (1) ingot fabrication, (2) hot forging, (3) hot and cold rolling and (4) thermal annealing. The last process is known to influence strongly the properties of the products. The best impact property of the product was obtained at the annealing temperature of $1173-1223 \mathrm{~K}$. Fig. 1 shows microstructure of NIFS-HEAT-2 as a function of the final annealing temperature. The temperature of the best impact property corresponds to that of the most prominent precipitation. These precipitates were identified to be Tirich phase with high concentration of $\mathrm{C}, \mathrm{O}$ and $\mathrm{N}$. It is known that the increase in the level of $\mathrm{C}, \mathrm{O}$ and $\mathrm{N}$ can degrade impact properties of vanadium alloys. Formation of the Ti-rich precipitates scavenges interstitial impurities of $\mathrm{C}, \mathrm{O}$ and $\mathrm{N}$ in the matrix. The dissolution of the precipitates by annealing at higher temperature, on the other hand, again scatters the impurities to the matrix.

The precipitate states can be controlled by the heat treatment for dissolving the precipitates followed by the second heating for re-precipitation. Fig. 2 shows microstructure after annealing at $1373 \mathrm{~K}$ for 1 hour (heat treatment for precipitate dissolution) followed by reheating for 1 hour at temperatures from $873 \mathrm{~K}$ to $1373 \mathrm{~K}$. High density of precipitates was formed at 973K. The density of the precipitates decreased with temperature. Most of the precipitates were again dissolved at $1273 \mathrm{~K}$ and above. The hardening occurred already at $873 \mathrm{~K}$ which was thought to be due to submicroscopic precipitates.

The annealing for precipitate dissolution followed by re-heating for re-precipitation was investigated for the purpose of strengthening the alloy. Fig. 3 shows Vickers hardness with the time of re-heating at $873 \mathrm{~K}$ following the dissolution annealing at $1373 \mathrm{~K}$ for 1 hour. The investigation selected the re-heating time of 20 hours as the standard heat treatment for strengthening. Results of TEM observation after re-heating at $873 \mathrm{~K}$ for 20 hours are shown in Fig. 4. No precipitate image was observed with the conventional bright field imaging and weak-beam dark field (WBDF) imaging with the g vector of [110]. However, high density of tiny precipitates of 1 2nm were observed with the WBDF imaging with $g$ vector of [200]. They are responsible for the hardening

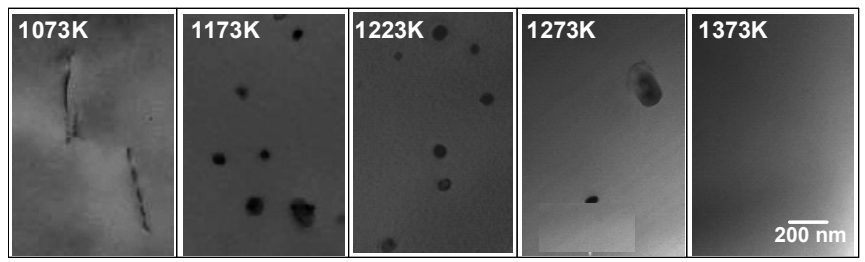

Fig. 1 Microstructure of V-4Cr-4Ti (NIFS-HEAT-2) as a function of final annealing temperature. The annealing was carried out for $1 \mathrm{~h}$.
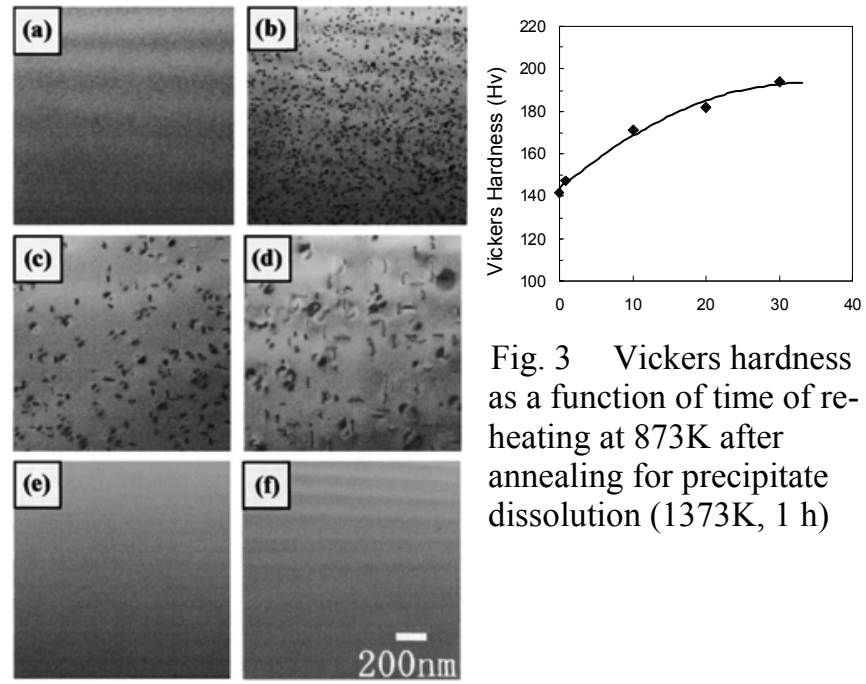

Fig. 3 Vickers hardness as a function of time of reheating at $873 \mathrm{~K}$ after annealing for precipitate dissolution $(1373 \mathrm{~K}, 1 \mathrm{~h})$

Fig. 2. Microstructure of V-4Cr-4Ti (NIFS-HEAT-2) as a function of re-heating temperature following annealing for precipitate dissolution $(1373 \mathrm{~K}, 1 \mathrm{~h})$. (a) $873 \mathrm{~K}$, (b) $973 \mathrm{~K}$, (c) $1073 \mathrm{~K}$, (d) $1173 \mathrm{~K}$, (e) $1273 \mathrm{~K}$ and (f) $1373 \mathrm{~K}$ for $1 \mathrm{~h}$
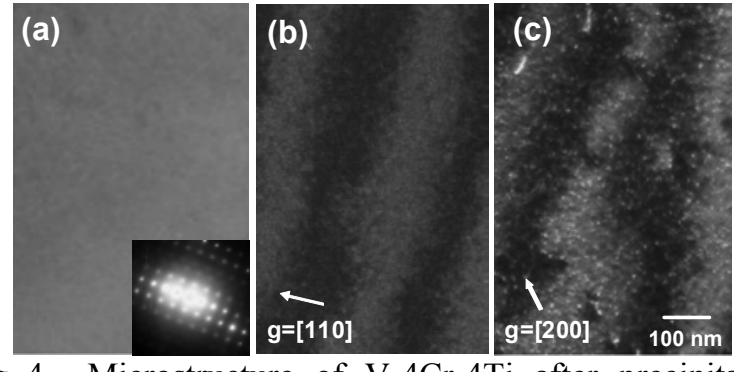

Fig. 4 Microstructure of $\mathrm{V}-4 \mathrm{Cr}-4 \mathrm{Ti}$ after precipitation hardening heat treatment (annealing at $1373 \mathrm{~K}$ for 1 hour for precipitate dissolution followed by re-heating at $873 \mathrm{~K}$ for $20 \mathrm{~h}$ for re-precipitation). The images by three diffraction conditions are compared. (a) Bright field image, (b) Dark field weak beam (DFWB) image with $5 \mathrm{~g}: \mathrm{g}=$ [110] and (c) DFWB image with 3g: $g=$ [200]. 